\title{
Improvement of solar cells efficiency and radiation stability by deposition of diamond-like carbon films
}

\author{
Nickolai I. Klyui ${ }^{1 *}$, Anatoliy N. Lukyanov ${ }^{1}$, Anatoliy V. Makarov ${ }^{1}$, Volodymyr B. \\ Lozinskii $^{1}$, Gennadiy S. Khrypunov ${ }^{2}$, Andriy N. Klyui ${ }^{3}$ \\ ${ }^{I}$ V. Lashkarev Institute of Semiconductor Physics National Academy of Sciences of Ukraine, Kiev, Ukraine \\ ${ }^{2}$ National Technical University "Kharkiv Polytechnic Institute", Kharkiv, Ukraine \\ ${ }^{3}$ Taras Shevchenko Kyiv National University, Kiev, Kiev, Ukraine \\ *Corresponding author.Tel: +38044 5256202,Fax:+38044 5256202,E-mail:klyui@isp.kiev.ua
}

\begin{abstract}
Diamond-like carbon films (DLC) deposited by PE-CVD technique were used as antireflection and protective coatings for $\mathrm{Si}$ and $\mathrm{A}^{\mathrm{II}} \mathrm{B}^{\mathrm{VI}}$ based solar cells (SC). Application of the DLC films as single- or doublelayer antireflection coatings allows us to improve the Si-based solar cells efficiency up to 1.4-1.5 times (from $\sim 10 \%$ to $\sim 15 \%$ ). It has been shown that optical bandgaps of DLC films were increased after UV irradiation. The films with greater amount of nitrogen show better irradiation resistance. It was also established that $\mathrm{Si}$ (both mono- and multicrystalline) and $\mathrm{A}^{\mathrm{II}} \mathrm{B}^{\mathrm{VI}}$ based SCs with even thin antireflection DLC film demonstrate higher stability against action of gamma-irradiation up to dose of $10^{8} \mathrm{rad}$. The effect is connected with hydrogen atoms those are released from the film as a result of broken of carbon-hydrogen bonds by $\gamma$ - or UV-quanta, diffuse to the SC, and passivate dangling bonds in the SC volume. It has been also shown that due to application of the DLC antireflection films with low refractive index the transparency of front ITO or $\mathrm{ZnO}(\mathrm{Al})$ contacts in $\mathrm{A}^{\mathrm{II}} \mathrm{B}^{\mathrm{VI}}$ based SCs may be substantially improved integrally to $10 \%$ in spectral range of $430-850 \mathrm{~nm}$. As a result, short circuit current and efficiency of thin film SCs may be also improved.
\end{abstract}

Keywords: Solar Cells, Antireflection Coatings, Radiation Stability

\section{Introduction}

At present diamond-like carbon (DLC) films are rather widely used as very promising antireflection (AR) and protective coatings for silicon solar cells (SCs) [1-3]. The main advantages of DLC films are high hardness, chemical and radiation stability, and the possibility to change their optical properties under the variation of deposition conditions. The last one allows formation of multi-layer antireflection and protective coatings for SCs just during the same technological process. Thus, it enables to avoid deposition of different antireflection layers, such as, for example, $\mathrm{SiO} 2, \mathrm{Si} 3 \mathrm{~N} 4, \mathrm{SiN}: \mathrm{H}, \mathrm{ZnO}, \mathrm{ZnS}, \mathrm{MgF} 2$ etc. As a result the technological procedure of antireflection layers formation becomes simpler and cheaper. Moreover, it was also shown that hydrogen containing DLC films may be successfully used as protective coatings for SCs against action of radiation. The improvement of radiation resistance of the SCs is still of great importance. One of the factors for space SC efficiency degradation is the action of proton and electron irradiation of "solar wind". It leads to reduction in carrier concentration of the base region and decreasing the minority carrier lifetime. One more part of "solar wind" is $\gamma$-irradiation. It is less dangerous but more penetrating than proton and electron particles. So, space SCs should have resistivity to penetrating irradiation like $\gamma$-quanta. So, the protective coatings must protect from radiation, improve the SC's optical properties and be radiation stable themselves. To achieve simultaneously the aim of protection, passivation and antireflection the diamond-like carbon thin films may be used both for space and terrestrial SCs.

In this paper antireflection and protective properties of the DLC films and their applications for improvement of SC efficiency and radiation stability were investigated. 


\section{Methodology}

The a-C:H:N films were deposited by the plasma-enhanced chemical vapor deposition method from the plasma of the RF discharge $(13.56 \mathrm{MHz})$ at various RF discharge powers $(100-250$ $\mathrm{Wt}$ ) and nitrogen contents in the gas mixture (10-45\%). The gas mixture $\mathrm{CH}_{4}: \mathrm{N}_{2}: \mathrm{H}_{2}$ was used, and the nitrogen content in it was varied by the gradual replacement of hydrogen by nitrogen. The gas pressure in a chamber was varied within the limits of 25-105 Pa. The film deposition was carried out onto substrates maintained at room temperature. The deposition time was $15 \mathrm{~min}$.

The thicknesses of DLC films were measured with a Dektak profilometer (the instrumental error was $\pm 5 \mathrm{~nm})$ and an LEF-3G laser ellipsometer $(\lambda=632.8 \mathrm{~nm})$. The film topography was studied making use of a Digital Instruments scanning atomic force microscope (AFM) Nanoscope IV. Optical constants of the films were measured by using spectral ellipsometer. Measurements of the DLC film's transmission were conducted on the Fourier spectrometer firm "Perkin Elmer" Spectrum BX-II in the range $(400 \div 2000) \mathrm{cm}^{-1}$. The transmission spectra of the films deposited onto glass substrates were measured by an S2000 spectrometer (Ocean Optics, USA) in the range $300-800 \mathrm{~nm}$.

Solar cell samples were fabricated on single- or multi-crystallite p-silicon, according to the technological routine which included diffusion of the doping impurity (phosphorus) from a $\mathrm{POCl}_{3}$ source, formation of the front contacts by the screen printing method (multi-Si) or the photolithography method (mono-Si), formation of the Al back contacts. Some of the fabricated specimens of solar cells were irradiated by $\gamma$-quanta from a $\mathrm{Co}^{60}$ source to the exposure doses of $10^{5}, 10^{6}, 5 \times 10^{6}, 10^{7}, 5 \times 10^{7}$, and $10^{8} \mathrm{rad}$. The SCs with and without thick DLC films were subjected to proton implantation $\left(\mathrm{E}=50-150 \mathrm{keV}, \mathrm{D}=1.10^{14}-1.10^{16} \mathrm{~cm}^{-2}\right)$. The proton depth distribution was calculated by Monte-Carlo simulation using TRIM-98 program. Some of DLC films and DLC - Si SCs structures were subjected to ultraviolet (UV) and focused UV (by 350 times) irradiation using light of Hg-lamp during 2 hours.

The solar cell samples were used to study the spectral dependences of the short circuit photocurrent and the light current-voltage load characteristics (LCVLCs). For this purpose, a special original certified setup was used [4]. The LCVLCs were used to determine the density of the short circuit current $J_{s c}$, the open-circuit voltage $V_{\text {oc }}$, the fill factor FF of the currentvoltage characteristic, and the SC efficiency $\eta$. The spectral dependences were measured in the wavelength range $400-1200 \mathrm{~nm}$. The spectral characteristics that had been obtained were used to determine the effective diffusion length $L$ of minority charge carriers in the base region of SCs.

\section{Results and Discussion}

\subsection{Application of DLC films as antireflection coatings for silicon solar cells}

It is well-known that for optimal antireflection effect when single-layer antireflection coating is used refractive index of an antireflection coating must meet completely the equation

$n_{\text {film }}=\left(n_{\text {substrate }}\right)^{1 / 2}$

where $n_{\text {film }}$ and $n_{\text {substrate }}$ are refractive indexes for substrate and antireflection film, respectively.

Refractive index of $\mathrm{Si}$ in spectral range where Si-SCs are photosensitive changes from 3.7 to 
5.5. It means that for Si-based SCs the $\mathrm{n}$ value must be $\sim 1.92-2.3$, and on the average must be close to 2.0. As we can see from Fig. 1 so-called "hard" film satisfied this conditions very good in rather wide spectral range.

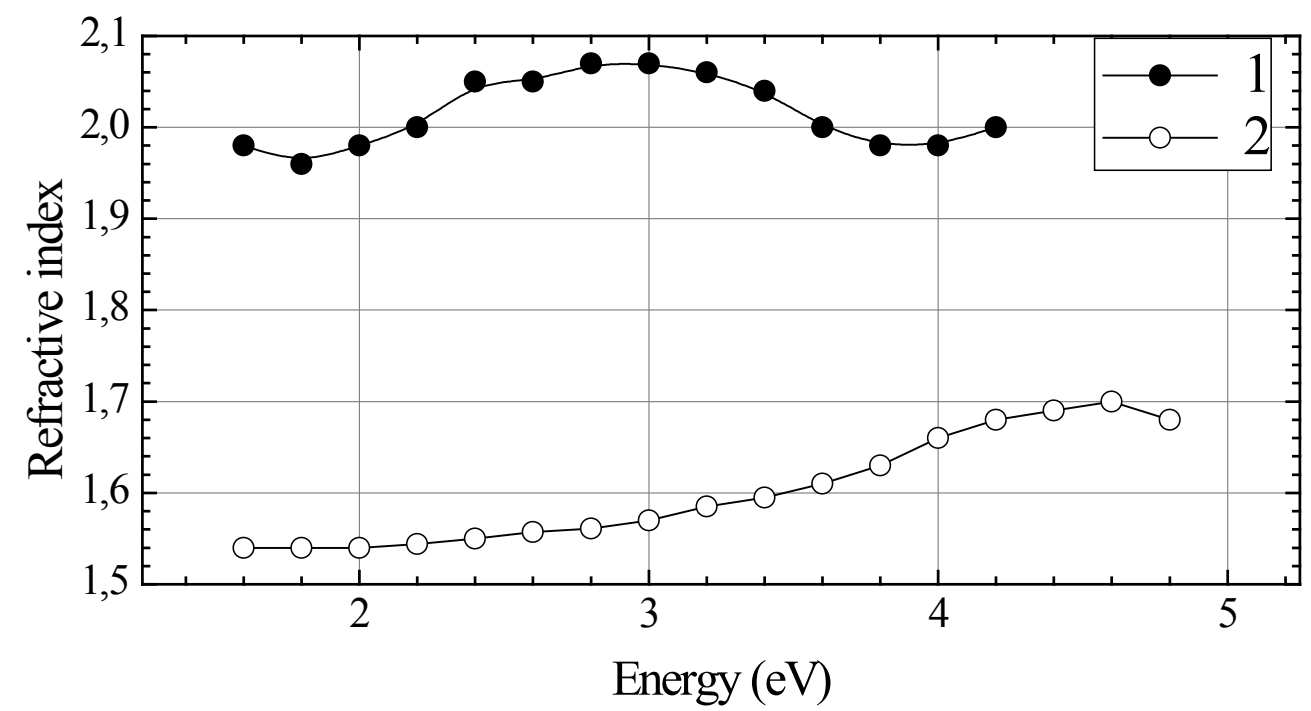

Fig. 1. Spectra of refractive index $n(E)$ of "hard"(1) and "soft" (2) DLC films. Nitrogen content in gas mixture is $1-0 \%, 2-45 \%$.

Indeed, as its seen from Table 1, after deposition of single layer (SL) or double layer (DL) DLC films significant increasing of the SC efficiency (up to 1.5 times) is observed due to not only simple antireflection effect (short circuit current density $\mathrm{J}_{\mathrm{sc}}$ increasing) but due to passivation of recombination active centers by hydrogen (fill factor FF and open circuit voltage $\mathrm{V}_{\text {oc }}$ increasing) as well [2]. It was also established that the $\mathrm{FF}$ and $\mathrm{V}_{\text {oc }}$ improvement effect is more pronounced for low quality SCs with high concentration of recombination active centers. On the whole, hydrogenation is very effective method for modification of defect recombination activity in $\mathrm{Si}$, especially in multicrystalline-Si where high concentration of defects at grain boundaries exist. It should be noted that hard and stable DLC films also acts as a barrier against hydrogen diffusion from the SCs.

The SCs parameters were measured under AM 1.5 spectral conditions.

Table 1. Parameters of SCS with and without DLC antireflection coatings.

\begin{tabular}{cccccc}
\hline Sample number & $\begin{array}{c}\mathrm{I}_{\mathrm{sc}} \\
(\mathrm{mA})\end{array}$ & $\begin{array}{c}\mathrm{J}_{\mathrm{sc}} \\
\left(\mathrm{mA} / \mathrm{cm}^{2}\right)\end{array}$ & $\begin{array}{c}\mathrm{V}_{\mathrm{oc}} \\
(\mathrm{V})\end{array}$ & Fill factor & $\begin{array}{c}\text { Efficiency } \\
(\%)\end{array}$ \\
\hline Initial 1 & $59.5 \pm 0.93$ & $25.54 \pm 0.40$ & $0.598 \pm 0.001$ & $0.722 \pm 0.001$ & $11.03 \pm 0.51$ \\
Initial 1 covered by & $80.3 \pm 0.93$ & $34.4 \pm 0.40$ & $0.607 \pm 0.001$ & $0.754 \pm 0.001$ & $15.74 \pm 0.62$ \\
SL-DLC* coating & & & & & \\
$\quad$ Initial 2 & $66.4 \pm 0.25$ & $24.3 \pm 0.11$ & $0.600 \pm 0.001$ & $0.677 \pm 0.001$ & $9.88 \pm 0.43$ \\
Initial 2 covered by & $91.4 \pm 0.93$ & $34.3 \pm 0.40$ & $0.613 \pm 0.001$ & $0.707 \pm 0.001$ & $14.87 \pm 0.53$ \\
DL-DLC* coating & & & & & \\
\hline
\end{tabular}

*The refractive index and thickness for the coatings 1 and 2 are: $2.03,71 \mathrm{~nm} ; 2.03 / 1.6$, $71 / 108 \mathrm{~nm}$, respectively. The films parameters were measured by laser ellipsometer at $\lambda=632.8 \mathrm{~nm}$.

On the other hand, in case that the DLC films are used as antireflection coatings for materials with rather low refractive index value the films with as low as possible $n_{\text {film }}$ value must be 
deposited. We can satisfied this requirement by changing the DLC film deposition conditions. For example, we can decrease the rf discharge power, increase the gas pressure in plasma reactor during film deposition and add nitrogen and oxygen to gas mixture [5]. As a result, the film with rather low $n_{\text {film }}$ value in wide spectral range may be obtained (so-called "soft" film) (Fig. 1).

It should be also noted that deposition rate of the DLC film may be rather high. For example, the SL-DLC film with refractive index $\sim 2.0$ and thickness of $71 \mathrm{~nm}$ may be deposited at 200 Wt discharge power during 3.5 minutes (Fig. 2). The deposition rate depends on rf discharge power and nitrogen content in gas mixture (Fig. 2).

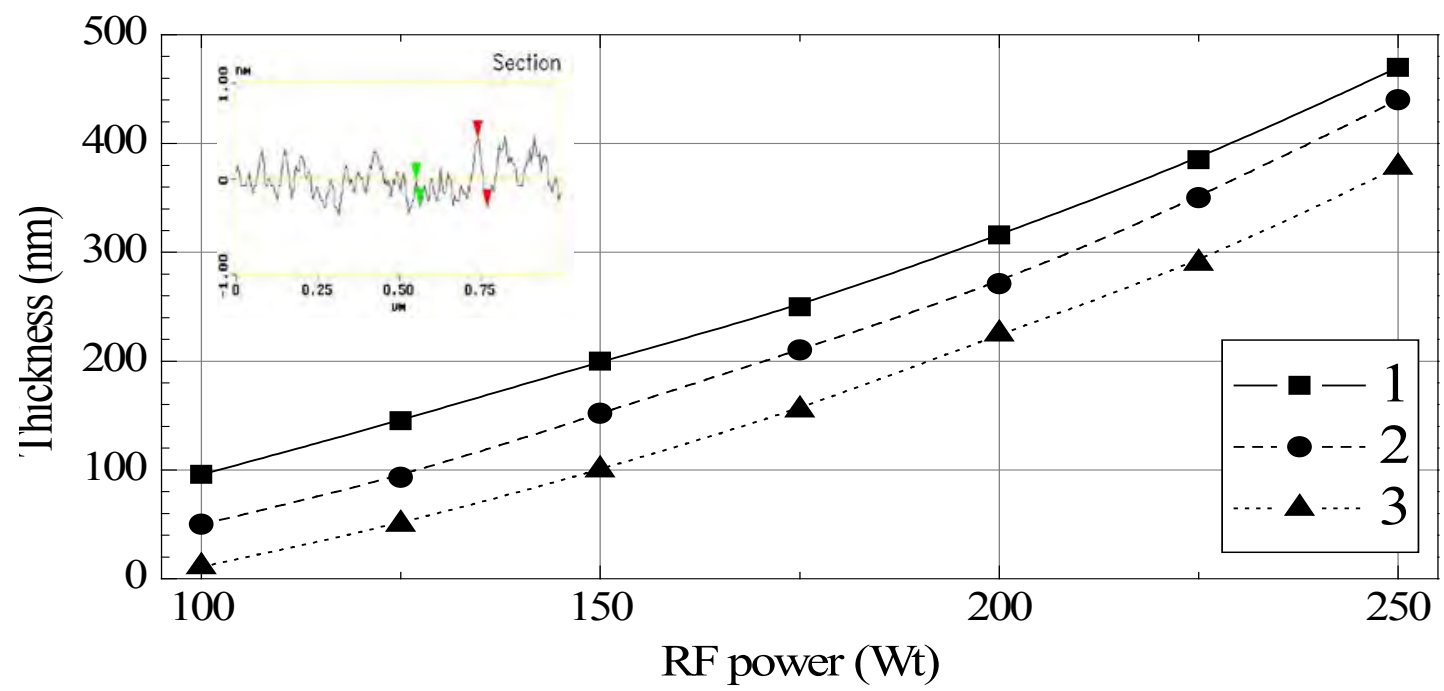

Fig. 2. Dependencies of the DLC (a-C:H:N) film thickness on RF power discharge. Deposition time is 15 minutes and nitrogen content in gas mixture is equal: $1-20 \% ; 2-30 \% ; 3-45 \%$. Inset shows roughness of the DLC films measured by AFM.

Investigations of the DLC film surface by atomic force microscope show that the films have high surface homogeneity with the average roughness less than $0.65 \mathrm{~nm}$ (see insert to Fig. 2).

\subsection{Application of thick DLC films as protective coatings}

For application of DLC films as protective coatings for SCs of space application as thick as possible films should be deposited to prevent degradation of SCs under action of so-called "solar wind". The films must possess proper optical properties, namely high transparency to decrease absorption losses in the film. It was earlier shown that nitrogen containing DLC films have low level of internal mechanical strains [6]. It allows us to deposit rather thick films. We studied SC-DLC film structures with the film thickness of $1300 \mathrm{~nm}$. Test SC without any protective film was also studied.

The SCs were subjected to implantation of protons of different energies $(50-150 \mathrm{keV})$ and doses $\left(10^{14}-10^{16} \mathrm{~cm}^{-2}\right)$. Fig. 3 shows dose dependencies of efficiency $(\eta)$ for the test SC and the SCs covered by DLC (a-C:H:N) protective film. In order to calculate depth distribution we used Monte-Carlo simulation (TRIM-98 program). It was established that for ion energies 50 and $100 \mathrm{keV}$ protons do not penetrate into Si SC and stopped in DLC films (Fig. 3). As we can see from Fig. 4 in this case decreasing of efficiency for the irradiated SCs is not observed up to high implantation dose $\left(10^{16} \mathrm{~cm}^{-2}\right)$. And only in case that proton energy is $150 \mathrm{keV}$ marked decreasing of the SC efficiency takes place at doses higher than $10^{15} \mathrm{~cm}^{-2}$. The degradation of the SC efficiency is caused by penetration of proton into the SC volume, 
generation of defects and reduction minority carrier lifetime in the SC [3]. The conclusion is confirmed by calculations and in this case proton mean projective range is close to DLC film - Si SC interface (Fig. 3).At the same time, unprotected SC become dramatically degraded at this dose and proton energy of $100 \mathrm{keV}$ (Fig. 3).

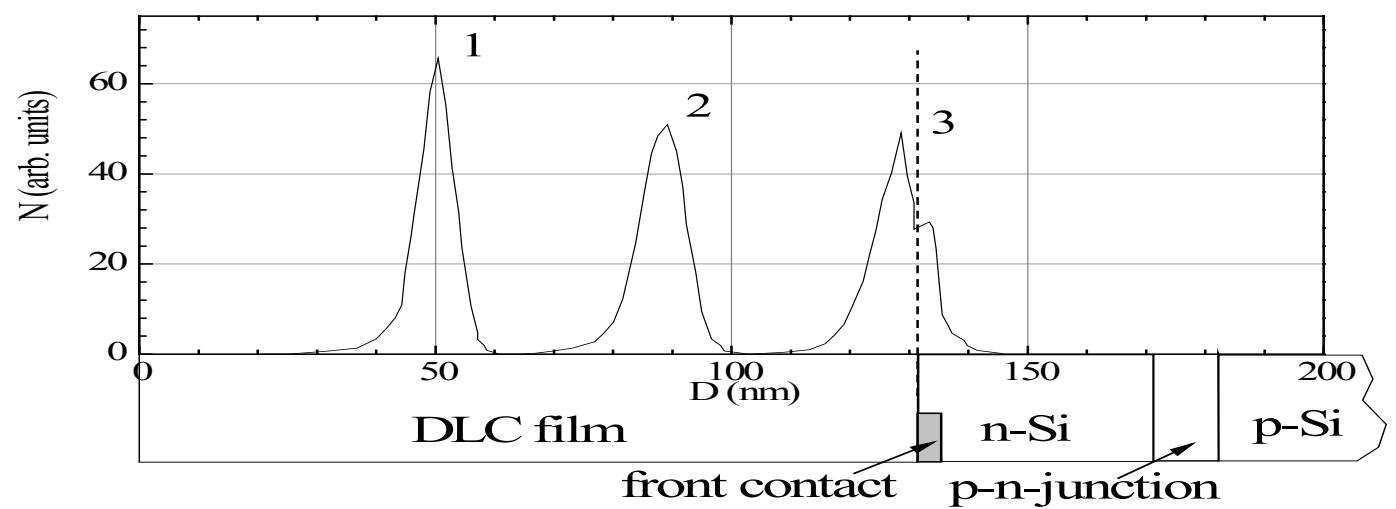

Fig. 3. Proton depth distribution of different energy in DLC film/Si-solar cell structure: 1 - $50 \mathrm{keV}$; 2 $-100-k E v ; 3-150 \mathrm{keV}$.

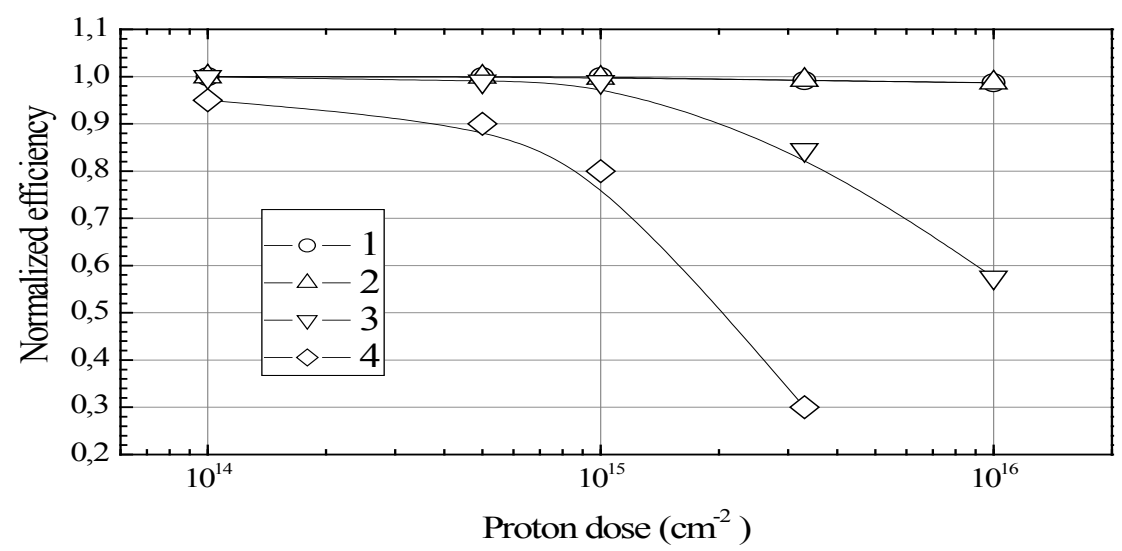

Fig. 4. Dependencies of normalized efficiency of solar cells from proton doses of different energy: 1 $50 \mathrm{keV} ; 2-100-\mathrm{kEv} ; 3-150 \mathrm{keV} ; 4-100 \mathrm{keV}$, solar cell without DLC coating.

\subsection{Application of thin DLC films as protective coatings}

Figs 5 and 6 present results of investigations of Si SCs subjected to $\gamma$-irradiation. It is seen from Fig. 4, that radiation resistance of the SCs covered by DLC films (curves 2, 4 in Fig. 5) is higher compared to unprotected SCs (curves 1, 2 in Fig. 5).

It should be pointed out that in this case we used thin $(71 \mathrm{~nm})$ DLC antireflection coatings. The statistical significance of the variation in Fig. 5 did not exceed \pm 0.01 . Thus, for majority of points it is substantially lower than observed changes in normalized efficiency values. It should be noted that no marked changes of results presented in figs 5, 6 were observed in one year after $\gamma$-irradiation of the samples. So, the degradation stability of the SCs covered by DLC films is higher than that without any coatings. The effect is observed both for SCs produced from mono-crystalline silicon and from multi-crystallite one. We proposed the following mechanism of $\gamma$-radiation effect on Si SCs properties. The effect is connected with hydrogen atoms those are released from the film as a result of broken of carbon-hydrogen bonds by gamma-quanta, diffuse to the $\mathrm{SC}$, and passivate silicon dangling bonds at grain boundaries and in the SC volume. As a result, lifetime and, consequently, diffusion length of minor charge carriers in the SCs degrade slower in the SCs covered by the DLC films (Fig. 6) 
[7]. Effect of silicon dangling bonds passivation in the SCs volume is confirmed by appearance of absorption band near $580 \mathrm{c} \mathrm{m}^{-1}$ in infrared spectrum of irradiated DLC-SC structures (Fig. 7) those correspond to Si-H bonds.

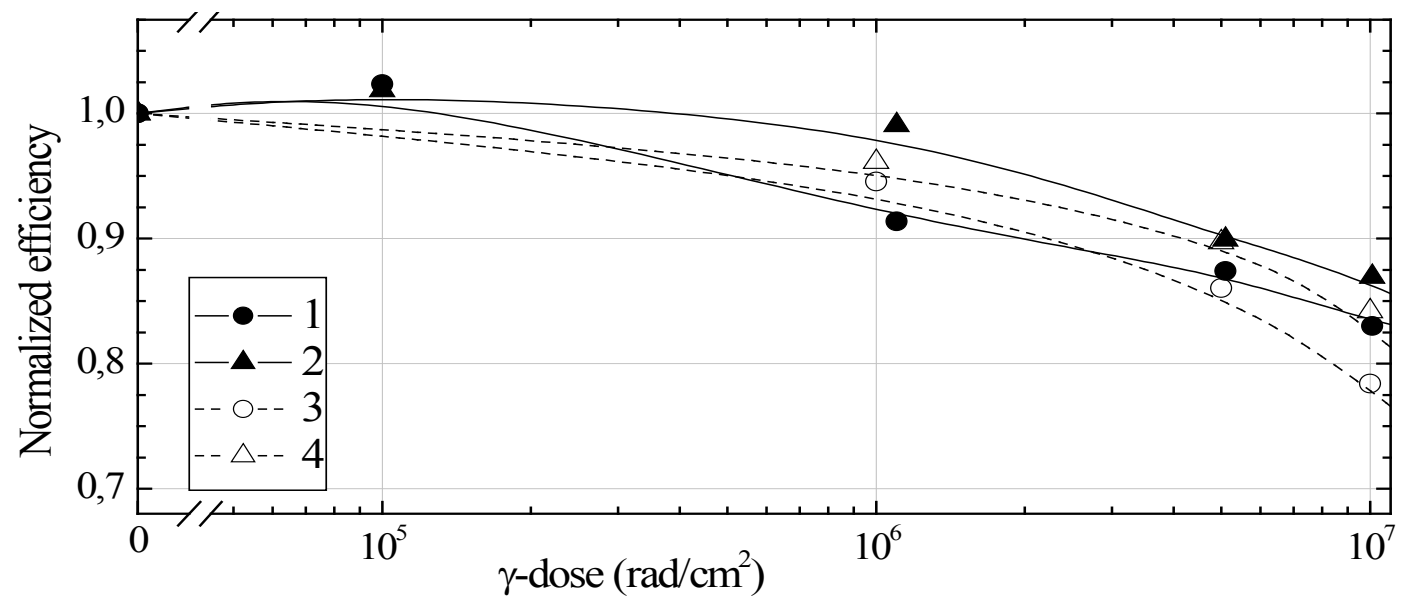

Fig. 5 Dependencies of normalized by initial value efficiency of solar cells from dose of $\gamma$ irradiation: 1 - mono-Si SC; 2 - mono-Si SC with DLC cover; 3 - multi-Si SC; 4 - multi-Si $S C$ with DLC cover.

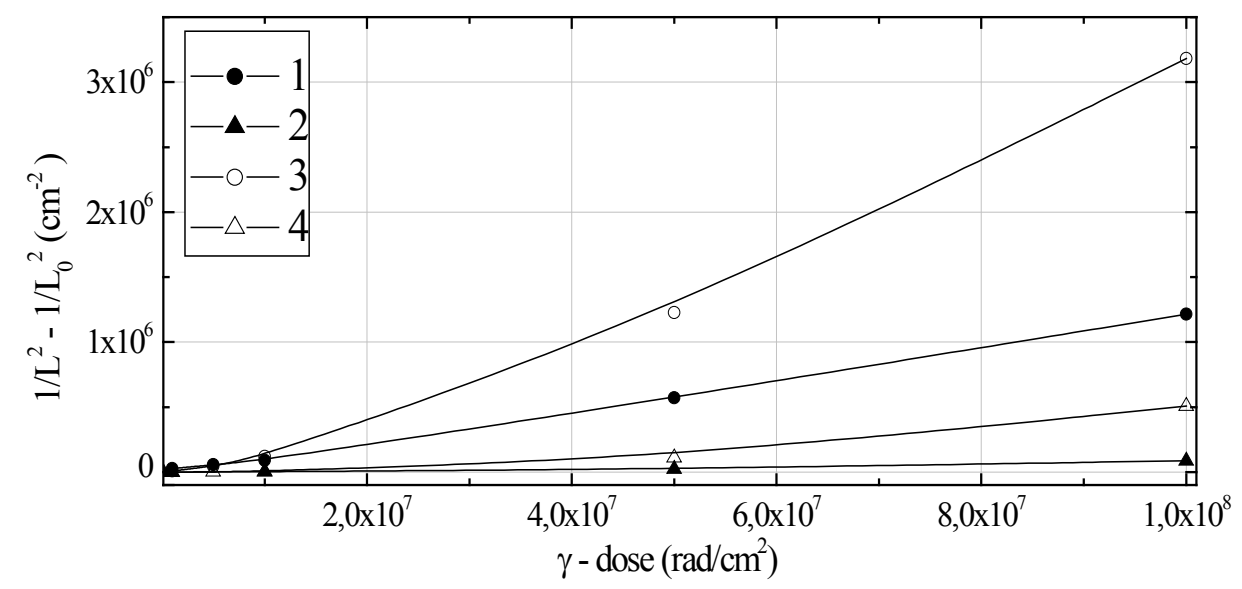

Fig. 6. Dependencies of $\left(1 / L^{2}-1 / L_{0}{ }^{2}\right)$ of solar cells on dose of $\gamma$-radiation: 1 - mono-Si SC; 2 - monoSi SC with DLC cover; 3 - multi-Si SC; 2 - multi -Si SC with DLC cover; Here $L_{0}$ and L are diffusion length of minor charge carrier of initial and irradiated SC, respectively.

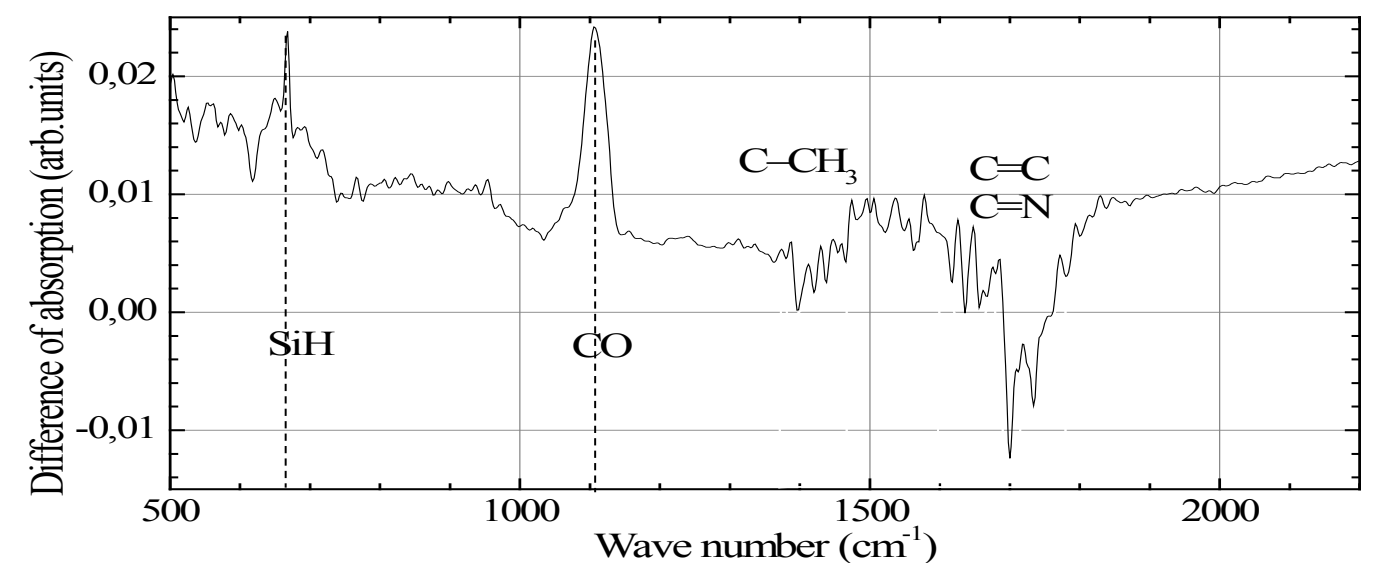

Fig. 7. Absorption difference between spectra of irradiated ( $\gamma$-irradiation dose $\left.10^{6} \mathrm{rad} / \mathrm{cm}^{2}\right)$ and initial DLC film deposited from precursor gar with $45 \%$ of $\mathrm{N}_{2}$. 


\subsection{Application of DLC films as antireflection coatings for materials with low refractive index}

$\mathrm{CdS}$, CdTe, CIS, and CIGS films are widely used for production of thin film or even flexible solar cells (SC). Because of low diffusion length of non-equilibrium carriers for the films it is especially important for such SCs to obtain highly conductive and transparent continuous front contact. As usual, for such contact indium-tin oxide (ITO) or $\mathrm{ZnO}$ doped with Al films are used. Refractive index of such films is higher than 2.0 [8] in the spectral region where the SCs are sensitive, therefore, rather significant reflection losses take place. In order to decrease the losses we propose to use diamond-like carbon (DLC) films with low refractive index to meet requirement for optimal antireflection effect. The DLC films were deposited by PECVD technique from gas mixture of nitrogen, methane and hydrogen. In some cases oxygen was also added to the gas mixture. As it was mentioned above we can deposit the DLC film with low refractive index (see Fig. 1). Theoretical modelling of optical properties for such multi-layered structures was also carried out to determine the required parameters of the antireflection DLC films. It has been shown that due to application of the DLC films transparency of front ITO or $\mathrm{ZnO}$ (Al) contacts may be substantially improved (Fig. 8). Further optimization of the DLC film deposition process allowed us to increase integral transmission of $\mathrm{ZnO}(\mathrm{Al})$ in spectral region $400-830 \mathrm{~nm}$ up to 1.1. times.. As a result short circuit current and efficiency of thin film SCs may be also improved.

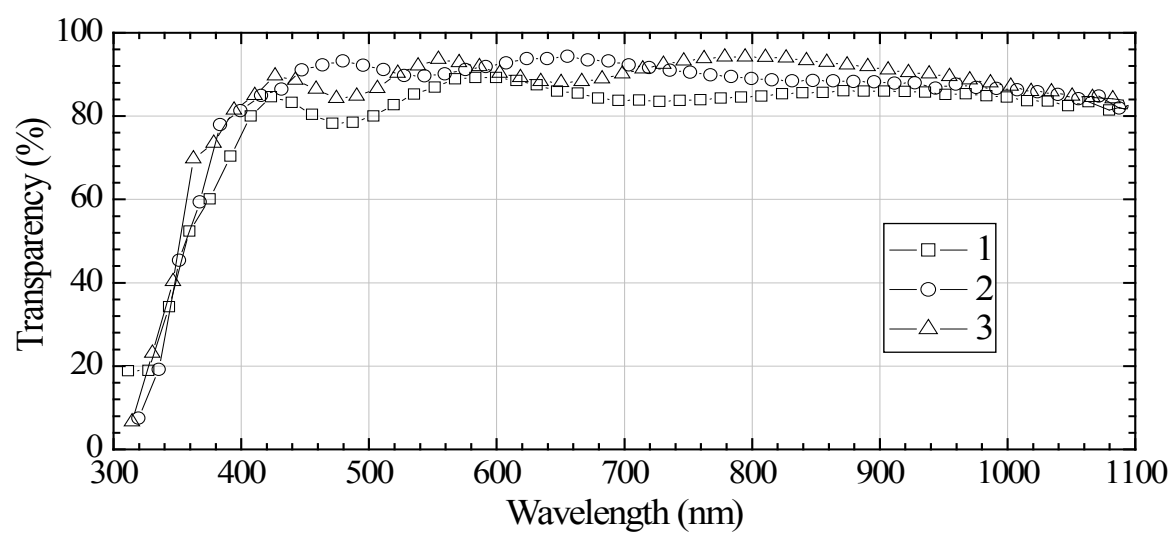

Fig. 8. Transparency of $\mathrm{ZnO}$ films $\left(30 \mathrm{Ohm} / \mathrm{cm}^{2}\right): 1$ - initial; 2 - covered by DLC film of $67 \mathrm{~nm}$ thickness; 3 - covered by DLC film of $100 \mathrm{~nm}$ thickness.

\subsection{Effect of ultraviolet irradiation on DLC films properties}

Diamond-like carbon films (a-C:H:N) were deposited by PE-CVD technique from gas mixture of nitrogen, methane and hydrogen. The films were irradiated by UV and focused UV (by 350 times) light of $\mathrm{Hg}$-lamp during 2 hours.

Transparency in visible and IR range and Raman spectra were measured. It has been shown that optical bandgap of the DLC films was increased after UV irradiation (Fig. 9). It was connected with oxygen incorporation into the DLC films, changing of carbon-nitrogen bonds concentration and graphite-like clusters size. The films with greater amount of nitrogen show better irradiation resistance. Because of increasing of the films optical bandgap after UV irradiation no changes of parameters for Si SCs covered by the DLC coatings after UV irradiation was observed. 


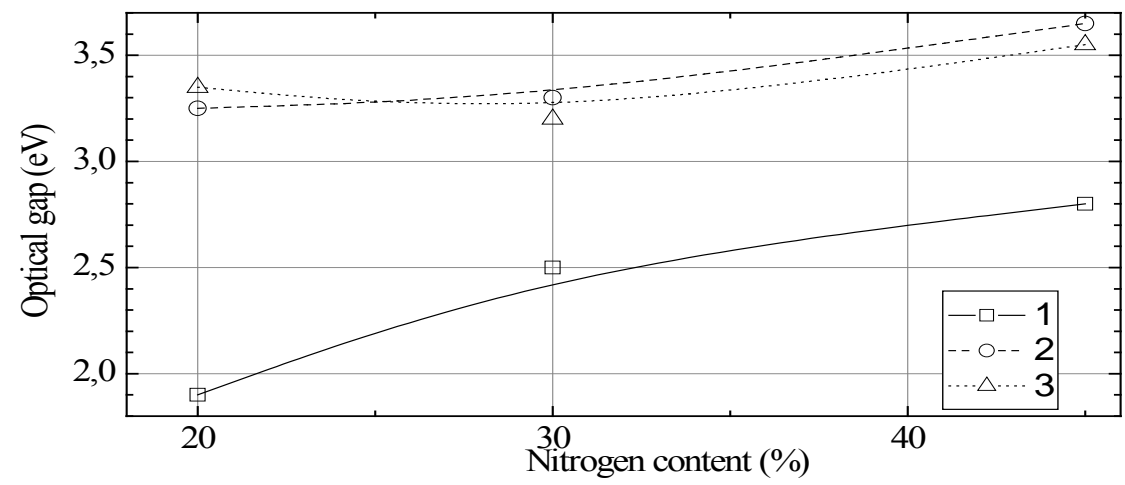

Fig. 9. Dependencies of DLC film optical energy gap on nitrogen content in gas mixture: 1 - initial DLC films; $2-U V$-irradiated DLC films; 3 -DLC films irradiated by concentrated UV light.

\section{Conclusions}

Finally, we may conclude that diamond-like carbon films are very prospective antireflection coatings not only for solar cells based on materials with high refractive index (like silicon) but for SCs prodused on the base of materials with low refractive index (like $\mathrm{A}^{\mathrm{II}} \mathrm{B}^{\mathrm{VI}}$ materials). In particular, efficiency of Si-based SCs may be improved up to 1.5 times due to deposition of the antireflection and passivative DLC films. It has been shown for the first time that even thin antireflection films $(\mathrm{d}=70 \mathrm{~nm})$ allows us to substantially improve radiation resistance of silicon based solar cells against action of $\gamma$-radiation with the dose up to $10^{8} \mathrm{rad}$. In its turn, thick DLC film $(\mathrm{d}=1300 \mathrm{~nm})$ enable to protect SCs against action of intermediate energy protons $(50-100 \mathrm{keV})$.

\section{Acknowledgements}

The work was supported by Science and Technology Center in Ukraine (project \#4301) and by the Ukrainian governmental scientific-technical program "Creation of chemicalmetallurgical branch for production of pure silicon in 2009-2012" (project \#4.2).

\section{References}

[1] M.Allon-Alaluf, The influence of diamond-like carbon films on the properties of silicon solar cells, Thin Sol. Films 303, No. 8, 1997, pp. 273-276.

[2] N.I. Klyui, Silicon solar cells with antireflection diamond-like carbon and silicon carbide films, Solar Energy Materials \& Solar Cells 72, 2002, pp. 597-603.

[3] V.G.Litovchenko, Solar Cells Based on DLC Film - Si Structures for Space Application, Solar Energy Materials \& Solar Cells 68, No.1, 2001, pp. 55-70.

[4] Certificate of accreditation for center of photoelectric converters and batteries testing. Given to V.Lashkaryov ISP NASU by Ukrainian governmental centers of standardization, metrology, and certification. Date of issue - 29.04.2003.

[5] G. Adamopoulosa, Electron cyclotron resonance deposition, structure, and properties of oxygen incorporated hydrogenated diamondlike amorphous carbon films Journal of Applied Physics 96, No. 10, 2004, pp. 5456-5461.

[6] D. F. Franceschini, Structural modifications in a-C:H films doped and implanted with nitrogen, Diamond and Related Materials 3, 1993, pp. 88-93.

[7] N.I. Klyui, Influence of $\gamma$-irradiation on the parameters of silicon-based solar cells, Ukrainian Physical Journal 52, No. 3, 2007, pp. 245-250.

[8] D.R. Sahu, Development of ZnO-based transparent conductive coatings, Solar Energy Materials \& Solar Cells 93, 2009, pp.1923-1927. 